\title{
SOBRE O GOVERNO DAS MEMÓRIAS ASPECTOS DE UM DOMÍNIO DO REAL
}

\author{
Vinícius Nicastro Honesko \\ UFPR
}

\begin{abstract}
RESUMO: A partir de considerações sobre questões relacionadas à teoria da história, o presente ensaio analisa como a produção de uma narrativa historiográfica contém alguns aspectos que podem também ser detectados nos atuais modos de gestão de informaç̃oes e governo político baseados em padrões da cibernética. Para tanto, num primeiro momento, expõe como as maneiras de operar na historiografia podem ser compreendidas a partir de uma poética do saber e, num segundo momento, entrelaça essa dinâmica aos padrões de gestão de probabilidades no âmbito das ciências físicas e sociais. Por fim, expõe como a produção de um real por meio do controle das probabilidades se tornou 0 eixo central para 0 domínio das experiências humanas em sua amplitude (desde a gestão das memórias às práticas de governo em sentido estrito).
\end{abstract}

PALAVRAS-CHAVE: Teoria da história; Cibernética; Poética do saber.

\section{ON A GOVERNMENT OF MEMORIES}

ASPECTS OF A DOMAIN OF THE REAL

ABSTRACT: From considerations on issues related to the theory of history, the he present essay analyses how an historiographical narrative production contains some aspects which can also be detected on the contemporary manners of management of information and political government based on cybernetic patterns. Therefore, at first it exposes how the ways of operating on historiography can be comprehended as a poetics of knowledge and, in a second moment, it intertwines this dynamic with the patterns of management of the probabilities in scope of the physical and social sciences. Lastly, it exposes how the production of a real by means of the control of the probabilities became the central axis to the domination of the human experiences in all its breadth (since the management of the memories until the government practices in the strict sense).

KEYWORDS: Theory of history; Cybernetics; Poetics of knowledge.

Vinícius Nicastro Honesko é professor adjunto de História Contemporânea na Universidade Federal do Paraná. 


\title{
SOBRE O GOVERNO DAS MEMÓRIAS ASPECTOS DE UM DOMÍNIO DO REAL
}

\author{
Vinícius Nicastro Honesko
}

As reflexões aqui apresentadas partem de premissas que, mais do que interdisciplinares, procuram carregar certo teor de indisciplinariedade. Desde essa instância limiar - que, portanto, não está em um campo disciplinar que possa ser dito próprio - é que são propostas questões que funcionem como propulsoras a uma reflexão sobre o papel político das análises teóricas (tanto de cunho historiográfico quanto teórico-literário; em suma, e de modo abrangente, no campo das chamadas humanidades) no contemporâneo: é possível elaborar um pensamento sobre a história que esteja à altura das urgências do presente? Como, ao refletir sobre a memória e a constituição de um saber sobre o passado, abrir um flanco de batalhas no e para o presente sem o engessamento de um academicismo? $\mathrm{E}$, de maneira mais genérica, qual o papel político num presente desagregador - tal como este que se nos mostra como inexorável - de alguém que se disponha a refletir sobre as relações entre os modos de constituição da história e o presente (e isso sem cair no quase solipsismo de área - o historiador - que ainda clama por certa historia magistra vitae)? Aqui, não há pretensão de apresentar respostas, mas ao menos deixar que as perguntas ecoem e não sejam abafadas pela balbúrdia sonora das palavras de ordem que parecem, por todos os lados, nos impelir à irreflexão e a uma superficial tomada cega de partido neste tecido de curtidas que parece ter se tornado nosso único mundo possível.

Em 2002, a poeta polonesa Wisalawa Szymborska - nascida em 1923 e que, portanto, é pertencente à geração entre-guerras na Polônia: e isso quer dizer, como lembra sua tradutora, Regina Przybycien, que ela teve de lidar tanto com a experiência traumática da guerra quanto com as quatro décadas de comunismo - , publica Instante. ${ }^{1}$ No livro está incluído um pequeno poema que pode funcionar, nestas breves considerações, como uma espécie de mote:

\footnotetext{
${ }^{1}$ PRZYBYCIEN, Regina. A arte de Wislawa Szymborska. In: SZYMBORSKA, Wislawa. Poemas. Trad. Regina Przybycien. São Paulo: Companhia das Letras, 2011, p. 12.
} 
Quando pronuncio a palavra Futuro,

A primeira sílaba já se perde no passado.

Quando pronuncio a palavra Silêncio,

Suprimo-o.

Quando pronuncio a palavra Nada,

Crio algo que não cabe em nenhum não ser. ${ }^{2}$

O incômodo da poeta se mede pelos modos de pensar como a linguagem pode mediar o mundo. Em outras palavras, estaria na ordem da capacidade de representação e de atribuição de sentido às experiências humanas no tempo, aliás, à própria experiência do tempo e aos modos de dizer o tempo e de dar conta tanto da historicidade das ações (o modo como às ações correspondem maneiras de compreendê-las em certo contexto) quanto de também perceber a possibilidade de representação do tempo no jogo da presença no mundo dos viventes que refletem sobre sua presença e o tempo no mundo.

O poema provoca uma espécie de curto-circuito que há muito parece importunar os viventes humanos. Sem me alongar numa longa digressão e apenas para nomear alguns exemplos, lembro que reflexões sobre o tempo e a história - num âmbito por assim dizer moderno (claro que, por exemplo, Agostinho já tinha uma refinada reflexão sobre a dimensão da interioridade da experiência temporal'3) - já estão, como anotou Reinhart Koselleck, ${ }^{4}$ no seio da problemática que atravessa a própria constituição do conceito mesmo de história: desde os fins do século XVIII nos debates sobre a Geschichte e a Historia na Alemanha, passando com novas roupagens por Hegel e o subsequente debate promovido pelos românticos, estruturando-se de maneira a dar suporte a um novo modo de compreender a organização da vida em sociedade em Marx, abrindo para Nietzsche um caminho ao pensamento do eterno retorno e, com nuanças e peculiaridades, chegando a um pensamento sobre a historicidade (sobre historialidade, seria possível dizer) de um pensador como Heidegger, que pretendia, com uma maneira ontológica de encarar a temporalidade, apontar para uma suposta experiência original dos homens (o ser lançado no mundo: o ser-aí).

2 SZYMBORSKA, Wislawa. Poemas. Trad. Regina Przybycien. São Paulo: Companhia das Letras, 2011, p. 107.

${ }^{3}$ Cf. GAGNEBIN, Jeanna Marie. Dizer o Tempo. In: Sete Aulas sobre linguagem, memória e história. Rio de Janeiro: Imago, 2005, p. 67-78.

${ }^{4}$ Cf. KOSELLECK, Reinhart. A Configuração do moderno conceito de história. In: Idem; MEIER, Christian; GÜNTHER, Horst; ENGELS, Odilio. O Conceito de História. Trad. René Gertz Belo Horizonte: Autêntica, 1975, p. 119-184. 
O jogo da historicidade, da compreensão da presença no mundo, pode ser remetido, nesse sentido, às experiências humanas mais variadas: no âmbito da dita cultura ocidental, desde as narrativas míticas de justificação da presença no mundo, passando pelas inquisições - os problemata - da chamada filosofia, até às experiências da ciência moderna e contemporânea. Aliás, tal jogo talvez possa ser até mesmo reconduzido aos modos como passamos a nos dizer e identificar enquanto uma espécie, isso que pode ser denominado de antropogênese. Nesse sentido, lembra Peter Sloterdijk, num exercício imaginativo para compreender o que ele chama de hiperpolítica, que é preciso deixar a negligência em relação ao que denominamos pré-história e afrontá-la, mesmo que no âmbito da imaginação, como o lugar por excelência em que a antropogenênese começa a acontecer. Para o filósofo, apenas obliterando esse longo processo em que o homem produz o homem é que posteriormente algo tão lato como um o conceito de humanidade pôde ser cunhado. Aliás, para ele esse conceito parece nascer, ao menos no Ocidente, por meio de uma fixação pelas grandes civilizações, uma espécie de mentira básica no âmbito da história. Essa fixação, diz

\begin{abstract}
destrói, pelo menos em última instância, a unidade da evolução humana e desliga a consciência atual da cadeia das inúmeras gerações humanas que elaboraram nossos "potenciais" genéticos e culturais. Ela ofusca a visão do acontecimento fundamental que se antecipa a toda grande civilização e do qual todos os chamados acontecimentos históricos só são derivações posteriores - o acontecimento global: antropogênese. A apologia atual da grande civilização abrevia a história da humanidade em mais de $95 \%$, talvez até em $98 \%$ de sua duração real, a fim de ter liberdade para uma doutrinação ideológica e antropológica em alto grau - a doutrina, entendida como clássica e moderna, do homem como um "ser político". ${ }^{5}$
\end{abstract}

Assim, essa imaginação que pretende pensar a espécie nos termos de uma paleopolítica constituiria um modo de nos afastar da obsessão pelas grandes civilizações e tornaria possível algo como a exibição do paradoxo por excelência da política, cuja formulação poderia ser: "pertencer-se com aqueles com os quais não se pertence. [...] não espanta que a história das ideias políticas sempre tenha sido uma história dos fantasmas da pertença". ${ }^{6} \mathrm{~A}$ despeito do caminho que trilhará o filósofo alemão - e de suas provocações irônicas - há em seu pensamento algo muito importante para refletirmos: a antropogêne-

${ }^{5}$ SLOTERDIJK, Peter. No mesmo barco: Ensaio sobre a hiperpolítica. Trad. Cláudia Cavalcanti. São Paulo: Estação Liberdade, 1999, p. 14-15.

${ }^{6}$ Ibidem, p. 19. 
se como um acontecimento cuja distante e indisponível origem longínqua no passado ainda é um operador sempre presente nos modos de organização da chamada vida social bem como de nossa compreensão - ocidental, ao menos - do estar no mundo. Em outras palavras, haveria uma espécie de controle do devir humano pelo próprio humano em termos de representação de si, isto é, uma instituição do que é o real humano. Ou ainda, essa forja de humanidade, um mecanismo representacional do humano, só poderia funcionar com base numa espécie de auto-percepção e, com isso, a instância da produção desse real estaria, paradoxalmente, presa naquilo que dá suporte para a superação do animal pelo humano: justamente a linguagem significante (ou, como diria Aristóteles, a phoné enarthros). Dentre os instrumentos (tekné) do homem (anthropos), a linguagem seria o mais fundamental ao fazer-se humano do humano (e a história da metafísica pode, de fato, ser lida nessa chave), seria o que dá as condições para a representação de si, para a compreensão da presença no mundo (e também da evasão do mundo: a morte), para a percepção do tempo, enfim, para a invenção disso que convencionamos chamar história.

"Existe história porque os seres falantes são reunidos e divididos por nomes, porque eles nomeiam a si mesmos e nomeiam os outros com nomes que não têm 'a mínima relação' com o conjunto de propriedades", 7 diz Jacques Rancière ao expor essa impropriedade constitutiva da história, ou seja, ao expor como não é possível pensar em termos de uma adstrita fixação de propriedade do vivente ao nome que o designa. Em outras palavras, Rancière aponta que o problema fundamental da constituição do vivente humano - o zoon logon ekon aristotélico - replica-se no âmbito das representações que os falantes constroem para si e para suas ações, isto é, na história. Diz ele: "Existe história precisamente porque nenhum legislador primitivo pôs as palavras em harmonia com as coisas". ${ }^{8} \mathrm{E}$ nesse intervalo, podemos acrescentar, instala-se a empreitada humana da constituição do que pode ser dito o real (tanto um real da história quanto, falando em termos genéricos, o real da existência humana).

Esse cenário em que é possível perceber a co-implicação profunda da estrutura dos seres falantes com a estrutura desse seu produto que denominamos história foi, ao menos no que diz respeito ao estopim para estas análises, decorrente do curto-circuito do poema de Szymborska. Falar, criar represen-

7 RANCIÈRE, Jacques. Os nomes da história: ensaio de poética do saber. Trad. Mariana Echalar. São Paulo: Unesp, 2014, p. 53.

8 Ibidem, p. 54. 
tações do mundo com palavras, é instaurar o real que, em certo sentido, exibe essa espécie de falha constitutiva dos falantes: jamais dizemos as coisas, sempre dizemos palavras que pretendem se referir às coisas (ou, para dizer com Walter Benjamin, comunicamos sempre a essência linguística da língua). ${ }^{9}$ Que o debate a respeito da possibilidade de representação com a linguagem tenha longa história no âmbito da história das ideias, dos debates filosóficos e das questões científicas é certo. No entanto, não aqui há a intenção de nele ingressar, mas de apenas pontuá-lo sobretudo porque o problema que ronda a história está por ele de todo atravessado. O que dizemos, no âmbito da história, é da ordem da constituição da própria história, aliás, do próprio da história.

É Michel de Certeau quem nos lembra de que a premissa básica a ser encarada no que diz respeito à historiografia é que "o real que se inscreve no discurso historiográfico provém das determinações de um lugar." 10 Isto é, a pretensão do historiador em representar uma realidade histórica por meio da escrita no presente acaba por ser camuflada nas condições de produção de tal discurso. Certeau vai ainda mais longe e nos indica que "o passado é, também, ficção do presente. O mesmo ocorre em todo verdadeiro trabalho historiográfico. A explicação do passado não deixa de marcar a distinção entre o aparelho explicativo, que está presente, e o material explicado, documentos relativos a curiosidades que concernem aos mortos." ${ }^{11}$ Essa ficção, a narrativa, traz consigo a própria possibilidade da constituição da história (e daí Rancière falar que o saber histórico comporta uma poética do saber). A questão é que, nesse jogo da narrativa presente acerca do passado inacessível, posto que não existente como um objeto (para lembrar Marc Bloch), o real da história mostra seu lugar: no intervalo entre as palavras e as coisas; ou seja, o real da história se dá justamente naquilo que escapa à possibilidade de constituir, por paradoxal que pareça, o real das coisas na história. É Certeau mais uma vez a nos trazer elementos para pensar esse quase que imponderável real produzido:

A narrativa que fala em nome do real é imperativa; ela "faz conhecer", à maneira como se dá uma ordem. Nesse aspecto, a atualidade (o real cotidiano) exerce um papel semelhante ao que a divindade desempenhava outrora: os padres, as testemunhas ou os ministros da atualidade fazem com que ela fale para dar ordens em seu nome. [...] Ainda mais: essa narrativa é eficaz. Ao pretender relatar o real, ela o fabrica. Ela é performática. Ela torna crível o que diz e faz agir por essa razão.

\footnotetext{
${ }^{9}$ Cf. BENJAMIN, Walter. Sobre a linguagem em geral e sobre a linguagem do homem. In: Escritos sobre Mito e Linguagem. Trad. Susana Kampff e Ernani Chaves. São Paulo: Ed. 34, 2011, p. 4974.

${ }^{10}$ CERTEAU, Michel de. A Escrita da História. Trad. Maria de Lourdes Menezes. Rio de Janeiro: Forense, 2013, p. 23.

11 Ibidem.
} 
Ao produzir crentes, ela produz praticantes. [...] As vozes charmosas da narração transformam, deslocam e regulam o espaço social; elas exercem um imenso poder que, por sua vez, escapa ao controle por se apresentar como a verdadeira representação do que se passa ou do que se passou. ${ }^{12}$

É para a constituição da prática historiográfica como produtora de uma possível instância do real que Certeau chama a atenção. Entretanto, ele ressalta que essa forja do real está totalmente articulada com o lugar desde onde esse discurso historiográfico se produz:

\begin{abstract}
Para combinar uma encenação com um poder, o discurso vincula-se à instituição que lhe garante, ao mesmo tempo, a legitimidade diante do público e a dependência em relação à dinâmica das forças sociais. O empreendimento assegura o papel ou a imagem como discurso do real para os leitores ou espectadores, ao mesmo tempo que, por seu funcionamento interno, ele articula a produção sobre o conjunto das práticas sociais. Mas existe interação entre esses dois aspectos. As representações são autorizadas a falar em nome do real apenas na medida em que elas fazem esquecer as condições de sua fabricação. ${ }^{13}$
\end{abstract}

No âmbito da historiografia, portanto, está em jogo a constituição de um saber que performaticamente produz seu próprio objeto. Nesse sentido, que tipo de ciência seria essa? Tal questão não é retórica, mas afronta um dos problemas elementares para a constituição dos saberes no âmbito das assim chamadas humanidades. Esse real produzido, por assim dizer, é o que se compõe numa narrativa histórica - mas também nas informações sobre o cotidiano, nas práticas de governo etc.. Entretanto, para que seja produzido depende de um esquecimento preliminar, tal como fala Certeau, de seu próprio pressuposto, aquilo que não pode ser formalizado, simbolizado por meio da linguagem (e aqui o debate poderia remeter à antiga discussão sobre a "coisa em si" e o "fenômeno"). A respeito desse ponto cego, por assim dizer, nos esclarece Alain Badiou:

Isso quer dizer que aquilo que a formalização torna possível [...] só é possível pela existência implicitamente assumida daquilo que não pode se inscrever nesse tipo de possibilidade. Trata-se, portanto, de um "ponto de pensamento" que, embora condenado a permanecer inacessível para as operações que a formalização torna possíveis, não deixa de ser a condição última da própria formalização. ${ }^{14}$

${ }^{12}$ CERTEAU, Michel de. História e Psicanálise: entre ciência e ficção. Trad. Guilherme João de Freitas Teixeira. Belo Horizonte: Autêntica, 2016, p. 53.

13 Ibidem, p. 54.

${ }^{14}$ BADIOU, Alain. Em busca do real perdido. Trad. Fernando Scheibe. Belo Horizonte: Autêntica, 2017, p. 30. 
Em certo sentido, esse esquecido nas condições de fabricação é o outro nome do real. Não desse real fabricado na narrativa (ou nas informações, ou nas práticas de governo), mas o real que é condição sine qua non da própria narrativa, o real que no âmbito da historiografia é impossível de ingressar na esfera da narrativa. Antes de me dedicar a uma análise sobre esse impossível que é o real que subjaz às narrativas (e ações) produtoras do real formalizado, gostaria de trazer uma pequena história sobre essa discussão também para um debate contemporâneo não só a respeito da historiografia, mas também sobre a constituição dos saberes científicos e, por fim, sobre questões políticas que vêm se tornando urgentes na era da integração informacional em rede. Trata-se do desaparecimento, em 25 de março de 1938, de Ettore Majorana, físico que em conjunto com Enrico Fermi, Edoardo Amaldi, Franco Rasetti, Emilio Segrè, Bruno Pontecorvo e Oscar D'Agostino fez parte do chamado grupo dos Rapazes da rua Panisperna, jovens cientistas - sobretudo físicos - italianos que entre 1929 e 1938 realizaram pesquisas fundamentais para o desenvolvimento da energia nuclear, sobremaneira a descoberta, em 1934, das propriedades dos nêutrons térmicos (que mostra a maior capacidade de certos nêutrons de serem absorvidos por outros elementos).

A respeito do sumiço do físico, o escritor Leonardo Sciascia publica, em 1975, um livro, que se tornaria um clássico na Itália, no qual expunha, como tese central das razões do desaparecimento de Majorana, a ideia de que, por pressentir o uso nefasto que a física teria tido em poucos anos com as recentes descobertas, o físico teria optado por desaparecer. Em um recente texto - Che cos'è reale ${ }^{15}$ - o filósofo italiano Giorgio Agamben acolhe em partes as ideias de Sciascia, mas, cruzando essa leitura com algumas outras - certas reflexões de Simone Weil sobre a física quântica e um artigo (de 1942) do próprio Majorana denominado $O$ valor das leis estatísticas na física e nas ciências sociais -, trata de alavancar sua hipótese integrativa à ideia de Sciascia: Majorana teria desaparecido depois de ter visto as consequências da introdução das noções de probabilidade no âmbito e nos próprios modos de funcionamento da física. Em suma, ele teria optado por sumir depois de perceber que "uma vez que se assuma que o estado real de um sistema seja em si não conhecível, os modelos estatísticos se tornam essenciais e só podem substituir a realidade." ${ }^{16}$ No limite, Majorana teria desaparecido como modo de fazer de sua pessoa "a cifra exemplar do estatuto do real no universo probabilístico

\footnotetext{
${ }^{15}$ AGAMBEN, Giorgio. Che cos'è reale?: La scomparsa di Majorana. Vicenza: Neri Pozza, 2016.
}

${ }^{16}$ Ibidem, p. 52. 
da física contemporânea" e, com isso, o físico teria produzido "um evento ao mesmo tempo absolutamente real e absolutamente improvável." ${ }^{17}$

Ao tomarmos a parte final do artigo de Majorana sobre o Valor das leis estatísticas na física e nas ciências sociais, iremos esbarrar - tal como acima pretendi fazer no que diz respeito à historiografia - em como o físico percebeu o modo que a física e as ciências sociais contemporâneas lidam com esse real impossivel de formalizar. Trata-se da assunção dos modelos estatísticos e probabilísticos como algo inexorável ao controle e gestão de um real. Assim o físico termina seu texto:

A desintegração de um átomo radioativo pode obrigar um contador automático a registrá-lo com efeito mecânico, tornado possível por amplificação adaptada. Bastam, portanto, artifícios comuns de laboratório para preparar uma cadeia complexa e vistosa de fenômenos que seja comandada pela desintegração acidental de um só átomo radioativo. Não há nada, do ponto de vista estritamente científico, que impeça de considerar como plausível que na origem de acontecimentos humanos possa se encontrar um fato vital igualmente simples, invisível e imprevisível. Se assim o é, como nós sustentamos, as leis estatísticas das ciências sociais veem crescer sua função, que não é apenas a de estabelecer empiricamente o resultado de um grande número de causas desconhecidas, mas, sobretudo, de dar um testemunho imediato e concreto da realidade, cuja interpretação requer uma arte especial, não menos importante, que serve de subsídio da arte de um governo. ${ }^{18}$

As leis estatísticas é que dariam testemunho do real concreto, isto é, tanto no âmbito das ciências físicas como humanas haveria, mais do que uma pretensão de conhecimento de um suposto real do mundo, algo como uma construção desse real por meio de um controle, de uma arte especial de governo do mundo. E, a partir disso, Agamben completa sua interpretação a respeito do desaparecimento de Majorana:

Como as leis probabilísticas da mecânica quântica visam não a conhecer mas a "comandar" o estado dos sistemas atômicos, assim as leis da estatística social visam não ao conhecimento, mas ao "governo" dos fenômenos sociais. [...] é possível, então, que a hipótese de Sciascia sobre as motivações que levaram Majorana a abandonar a física seja corrigida e integrada no sentido de que, se não é certo que Majorana tivesse vislumbrado as consequências da cisão do átomo, ao contrário, é seguro que ele tivesse visto com clareza as implicações de uma mecânica que renunciava a toda concepção não probabilística do real: a ciência não procurava

17 Ibidem, p. 53.

${ }^{18}$ MAJORANA, Ettore. II valore delle leggi statistiche nella Fisica e nelle Scienze sociali. In: AGAMBEN, Giorgio. Che cos'è reale?: La scomparsa di Majorana, op. cit., p. 78. 
mais conhecer a realidade, mas - como a estatística nas ciências sociais - apenas intervir nesta para governá-la. ${ }^{19}$

Nesse sentido, tanto as ciências físicas quanto as sociais pareciam apontar para um problema prático: o domínio das incertezas, ou, ainda, a gestão, administração, governo do que escapa a uma determinação direta e precisa. De fato, o problema se desvia para uma espécie de transformação das questões de incerteza em questões de informação, de formalização desse impossível real (mais uma vez): é preciso contar com os dados colhidos e ter em vista os prováveis e, nesse mecanismo, transformar a relação entre sujeito e objeto de conhecimento em um sistema que deve ser controlado de modo a auferir certos resultados (e essa maneira de operar estaria, portanto, em todo âmbito científico probabilístico).

O que as ciências, físicas ou sociais, começam a moldar - ou ainda, começam a aprimorar - são modelos específicos de previsibilidade para gerenciar tais sistemas de informações. Isto é, esses sistemas forjam-se como uma espécie de formalização com base no informalizável que só pode ser governado por meio da probabilística. Ainda em 1948, o matemático Norbert Wiener, em um livro denominado Cybernetics: or control and communication in the animal and the machine 20 - que, de certo modo, decorre de um projeto de desenvolvimento de uma máquina de predição e controle de aviões inimigos durante a II Guerra -, propõe a ideia de um modelo de controle das incertezas com base numa proposta de sistematização informacional que passou a ser conhecida como feedback (ou retroação): uma memorização de dados, acumulados então como repertório, que dá subsídios para estabelecer modos de controle de probabilidades vindouras. Era o nascimento da noção contemporânea de cibernética: um novo modo de intervenção no real por meio do controle e gestão das possibilidades e, assim, produção de estatísticas. ${ }^{21}$

Num âmbito mais amplo, essa noção carrega uma história absolutamente não descartável para o que estava surgindo. Etimologicamente cibernética ad-

19 AGAMBEN, Giorgio. Che cos'è reale?: La scomparsa di Majorana, op. cit., p. 19.

20 WIENER, Norbert. Cybernetics: or control and communication in the animal and the machine. Cambridge: MIT Press, 1948.

${ }^{21}$ Sobre a questão da cibernética e o problema da inscrição de um real - o problema da escritura do mundo no âmbito dos registros informacionais - também seria possível abrir todo um campo de discussão a partir das referências levantadas por Jacques Derrida em seu projeto gramatológico. Cf. DERRIDA, Jacques. Gramatologia. Trad. Miriam Chnaiderman e Renato Janine Ribeiro. São Paulo: Perspectiva, 2008. A análise da proposta derridiana - que, frise-se, faz referências a Wiener -, está prevista para os trabalhos futuros que darão continuidade a esta pesquisa. 
vém de Kybernétes, termo que, em grego, era utilizado para denominar o encarregado de pilotar uma embarcação, o responsável por governar os rumos do barco. Esse dado não escapa a Michel Foucault que, na aula de 17 de fevereiro de 1982, ressalta que essa noção de kybernétes - cuja tradução ao latim seria gubernator - estaria relacionada justamente a uma prática de governo, numa metáfora que atravessaria os séculos sempre ligada à dimensão das práticas médicas, do governo de si e do governo político. ${ }^{22} \mathrm{O}$ que, entretanto, acontece nas novas formatações da cibernética é que ela se estende - e uma expansão que se intensifica desde o início do século XXI de maneira jamais vista com a aceleração dos processos e protocolos de informação - para todas os âmbitos das práticas humanas. Em suma, a cibernética passa a ser parte das ações político-governamentais e dá vazão a uma espécie de concepção ofensiva da política. ${ }^{23}$ Isto é, a conformação de uma sociedade passa a ser vista como fundamentalmente atrelada à construção de um modelo social baseado no controle das probabilidades a partir da gestão desse real que se dá em forma sistêmica (feedbacks alimentam a máquina de gestar dados que, por sua vez, é o subsídio necessário para a narrativa real sobre o inatingível real do mundo).

A cibernética não é então apenas uma teoria, mas também uma tecnologia de intervenção direta e de governo da vida, bem como de reorganização das narrativas daquilo que pretendemos pensar como história. Assim, ao cruzarmos essa leitura com as hipóteses a respeito do papel das ciências - físicas e sociais - lembrados por Majorana e desenvolvidos por Agamben, parece mais claro que o desenvolvimento das práticas políticas e de governo tomaram rumos que excedem em grande medida as sistemáticas de gestão baseadas apenas em modelos representativos de amplo espectro (populações, demografias, localizações, determinações espaciais etc.; um nível macropolítico, por assim dizer). Isto é, com os avanços das tecnologias de informação no século $X X$ (e sua ainda mais radical aceleração no século $X X I$ ), o que quer que ocupe a posição de um kybernétes passa a contar com a possibilidade dos feedbacks, de uma ingerência direta por meio da construção de uma rede em que todos os traços dos indivíduos são por esses mesmos indivíduos informados (direta ou indiretamente; aqui, um nível micropolítico), salvos, mapeados e utilizados como pontos para um domínio absoluto da vida. Lembro aqui das análises feitas, ainda no fim do século XX, pelo interessante coletivo Tiqqun:

22 FOUCAULT, Michel. A Hermenêutica do sujeito. Curso dado no Collège de France (1981-1982). Trad. Márcio Fonseca; Salma Muchail. São Paulo: Martins Fontes, 2006, p. 303.

${ }^{23}$ Tiqqun. L'hypothèse cybernétique. In: Tout a faille, vive le communisme! Paris: La Fabrique, 2009, p. 235-236. 
A cibernética emerge, portanto, sob a forma inofensiva de uma simples teoria da informação, uma informação sem origem precisa, sempre já aí em potência no âmbito de toda situação. Ela pretende que o controle de um sistema se obtenha por um grau ótimo de comunicação entre as partes. Esse objetivo reclama, em primeiro lugar, a extorsão contínua de informações, processos de separação dos entes de suas qualidades, e produção de diferenças. Dito de outro modo, o domínio da incerteza passa pela representação e memorização do passado. De um lado, a imagem espetacular, a codificação matemática binária [...], a invenção de máquinas de memória que não alterem a informação e, de outro, o incrível esforço por sua miniaturização [...], conspiram para criar tais condições em nível coletivo. Assim conformada, a informação deve, na sequência, retornar ao mundo dos seres, religando-os uns aos outros, do mesmo modo que a circulação mercantil garanta seu colocar em equivalência. A retroação, chave da regulação do sistema, reclama agora uma comunicação no sentido estrito. A cibernética é o projeto de uma recriação do mundo por meio de laços infinitos desses dois momentos: a representação que separa, a comunicação que religa, a primeira doadora de morte, a segunda mimetiza a vida. ${ }^{24}$

É com base nesse horizonte que termos como sistemas interdependentes ganham realidade para além do sentido meramente informacional (e com meramente informacional quero dizer: como se a informação e os processos informativos - as tecnologias de informação - fossem sempre algo liso, neutro, transparente, apenas um canal de transmissão, um meio sem interferências). Isto é, a informação, desdobrada na representação (informa-se sobre algo) e na comunicação (o algo informado é transmitido como um dado linguístico), funciona como uma espécie de reprodução mimética da vida com o intuito de, em seguida, retornar à vida que não fora mimetizada enquanto informação (digamos, à vida que estamos vivendo ${ }^{25}$ ). Desse modo, com o retorno da

${ }^{24}$ Ibidem, p. 241-242.

25 Lembro das análises críticas de Agamben a respeito da separação operada na própria vida - uma vida separada de sua forma, ele diz em vários textos - que nos colocaria como espectadores impotentes da vida que passa: a ideia de uma vida que vivemos (vita quam vivimus, o que define uma biografia) e de uma vida pela qual e na qual vivemos (vita qua vivimus, o que torna a vida vivível e lhe dá sentido e forma). Nesse sentido, a operação cibernética é uma constante separação de uma vida definível em biografia, as informações representadas da vida no âmbito do sistema-rede, e o retorno dessa representação da vida ao vivente como modo de constituição de sua própria subjetividade. Ou seja, a vida pela qual e na qual vivemos apaga-se em prol das sobredeterminações das informações sobre a vida. Cumpre-se, com isso, uma perfeita separação no seio dos viventes que, nesse sentido, passam a ser o que e como se informam a respeito de si próprios. Se os dispositivos são parte do processo de subjetivação, na atual fase do capitalismo informacional eles são refinados e, com aparência libertária, são os modos mais sutis e ao mesmo tempo efetivos de domínio e de instauração de uma servidão voluntária. Cf. AGAMBEN, Giorgio. Il Regno e la gloria : Per una genealogia teologica dell'economia e del governo. Vicenza: Neri Pozza, 2007, p. 271-272. ; Idem. Il tempo che resta: Un commento alla Lettera ai Romani. Torino: Bollati Boringhieri, 2000, p. 67-68. E em sentido um pouco mais alargado, no último volume da série Homo Sacer. Cf. AGAMBEN, Giorgio. L'Uso dei corpi. Vincenza: Neri Pozza, 2014, p. 249-285. 
informação (o real formalizado) ao real (o real informalizável da vida), percebemos que as conexões entre técnicas, culturas, ideais, modos de vida não estão desvinculadas das cadeias de coisas reais que as formam: petróleo, eletricidade, produtos agrícolas, aliás, todas as esferas de existência dos viventes entram no registro informacional das equivalências ( $e$, no âmbito do século $X X$, mesmo o dinheiro, que funciona como princípio chave da equivalência geral, ingressa também no âmbito do registro informacional ${ }^{26}$ ). Ou seja, a cibernética e o modo operativo do capitalismo - cujo princípio motriz estaria na equivalência - estão umbilicalmente associados e, com isso, é impreterível não perder de vistas a dimensão do governo, do domínio, da e sobre a vida. ${ }^{27}$ Por outro lado, a cibernética, em seu projeto de recriação, em seu inserir-se capilarmente no aqui chamado real informalizável, em sua tentativa de controlar absolutamente esse real por meio do manejo das probabilidades, acaba por gerar uma esfera de projeção de possibilidades. Nessa armação de controle, muitas vezes tais possibilidades, úteis à manutenção do sistema, são, paradoxalmente, "ao mesmo tempo fantasmáticas e técnicas e têm suas próprias finalidades ou, de modo mais exato, cujas finalidades estão abertamente em sua própria proliferação, no crescimento exponencial de figuras e potências que valem por e para si mesmas, indiferentes à existência do mundo e de todos que nele existem." ${ }^{28}$ Nesse

${ }^{26}$ Cf. NANCY, Jean-Luc. Vérité de la démocratie. Paris: Galilée, 2008, p. 44. "O mundo democrático se desenvolveu no contexto - ao qual, na origem, está ligado - da equivalência geral. Tal expressão - mais uma vez, de Marx - não designa apenas o nivelamento geral das distinções e a redução das excelências na mediocrização [médiocrisation] [...]. Ela designa primeiramente a moeda e a forma mercantil, isto é, o coração do capitalismo. É preciso retirar daí uma lição muito simples: o capitalismo, no qual ou com o qual, ou ainda como o qual a democracia se engendrou, é, antes de mais nada, no seu princípio, a escolha de um modo de valorização: pela equivalência. $O$ capitalismo revela uma decisão de civilização: o valor está na equivalência. A técnica, também ela desenvolvida no e por efeito dessa decisão - do mesmo modo que a relação técnica com o mundo é de modo próprio e na origem aquela do homem -, é uma técnica submetida à equivalência: a de todos seus fins possíveis e, também, de maneira ao menos tão flagrante quanto no registro do dinheiro, a dos fins e dos meios."

${ }^{27}$ Em continuação a esta pesquisa também serão tratados, especificamente, os usos das tecnologias de informação como controle e manipulação do suposto real. Nesse sentido, teóricos da segurança em informação já alertam para um futuro distópico por conta dos modos de utilização de dados pelos chamados operadores de Big Data. Remeto aqui à entrevista com Aviv Ovadya, chefe do Centro de Responsabilidade de Mídias Sociais da Universidade do Michigan, que prevê um "infocalypse" que seria muito mais danoso do que os atuais escândalos ligados à venda de informações por parte de empresas de Big Data, como o mais recente - e vastamente divulgado - referente ao Facebook e a Cambridge Analytica (esta, a empresa contratada para as campanhas do Brexit e de Donald Trump à presidência dos EUA): Cf. WARZEL, Charlie. Ele previu a crise de notícias falsas de 2016. Agora está preocupado com um apocalipse de informações. BuzzFeed News, 23 mar. 2018.

${ }^{28}$ NANCY, Jean-Luc. L'équivalence des catastrophes (après Fukushima). Paris: Galilée, 2012, p. 28. 
sentido, é possível perceber certo limite da hipótese cibernética: sua sanha de controle pode, por vezes, embaralhar o informalizável com o formalizável (isto é, com os próprios dados informacionais que animam o sistema; lembremos das bolhas dos mercados financeiros, por exemplo, nas quais os lastros do real informalizável deixados de lado por vezes vêm assombrar o piloto invisível chamado Mercado).

É preciso lembrar, portanto, que o mundo por controlar é igual, mas e isso de modo paradoxal -, também totalmente diferente ao projetado: a vida, o real, o informalizável, não se consubstancia num traço informacional (a representação da vida, uma narrativa), porém, ao mesmo tempo, não deixa de ter sua duplicidade no chamado espaço cibernético - e isso acontece, em certa medida, da mesma forma na representação histórica. De modo reverso à hipótese Majorana, - que faz de um evento absolutamente real, seu desaparecimento -, algo absolutamente improvável, não se tem provas de seu desaparecimento, no tempo da gestão cibernética a identificação entre real e representação informacional se dá num âmbito irreal (aqui denominado real formalizado), mas não por isso improvável (os traços informacionais são hoje condições fundamentais para o controle, o governo, das probabilidades no mundo; no âmbito da economia, por exemplo, por meio deles se prova, a todo instante, o real do único mundo possível ${ }^{29}$ ). Eis a sagacidade e, ao mesmo tempo, o limite da hipótese cibernética e dos modos de gerir a vida ao menos desde a explosão da bomba em Hiroshima.

Nesse sentido, o alargamento das estruturas de controle - ou, se quisermos, de governo - do mundo e da vida depende cada vez mais de dispositivos de representação e memorização do passado, mas de um passado que, agora, tornou-se um dado, um traço, informacional gravado nesses mesmos disposi-

${ }_{29}$ Interessante apontar, mais uma vez, para Alain Badiou. Cf. BADIOU, Alain. Em busca do real perdido, op.cit., p. 11. "O que é impressionante na economia considerada como saber do real é que, mesmo quando enuncia - e às vezes é obrigada a isso pela evidência dos fatos - que o 'real' dela está fadado à crise, à patologia, eventualmente ao desastre, todo esse discurso inquietante não produz nenhuma ruptura com a submissão subjetiva ao real de que ela se gaba de ser o saber. Em outras palavras, o que a economia considerada como discurso do real diz, prevê ou analisa nunca fez senão validar o caráter intimidante desse famigerado real, e nos submeter sempre mais a ele. De tal modo que, quando esse real parece desfalecer, mostrar-se como uma pura patologia, devastar o mundo ou as existências - quando os próprios economias acabam por perdem o seu latim -, mesmo assim a soberania dessa intimidação pelo real econômico não apenas não é realmente reduzida como até se vê aumentada. Os economistas e seus financiadores reinam de maneira ainda mais imperial do que antes dos desastres que não souberam prever e só constataram depois, como todo mundo. O que prova muito bem que essa gente não se deixa destituir." Nesse sentido, também Frederic Jameson traz uma concepção dessa espécie de inexorável real quando diz: "Alguém disse uma vez que é mais fácil imaginar o fim do mundo do que o fim do capitalismo." Cf. JAMESON, Frederic. A cidade do futuro. Trad. Maurício Miranda dos Santos Oliveira. Libertas: Revista da Faculdade de Serviço Social / UFJF. Juiz de Fora, n. 10, v. 1, p. 195, 2010. 
tivos: desde nossos cartões de créditos, passando por nossos registros biométricos (cada vez mais utilizados pelos governos), por nossos registros digitais, ou seja, a capilarização do controle se dá com a proliferação de um ambiente em rede - e a internet é o modelo por excelência dessa nova dimensão informacional da vida. ${ }^{30}$ Em suma, a cibernética funciona também a partir das analogias que estabelece - e que se imiscuem cada vez mais no real informalizável, digamos - entre o funcionamento dos organismos vivos e das máquinas, o que gera uma mecânica dos vivos, com vistas à programação e dominação, num controle do devir social que guiaria a um suposto fim da História, e uma vitalização das máquinas, que no terreno da comunicação gera justamente a noção de rede (basta lembrar dos smartphones).

Diante de perspectivas como estas, a impotência de fato parece ser a única sensação legítima. No entanto, nesse mesmo horizonte terrificante de uma forja de real formalizável por meio de um controle do real informalizável pelo sistema, paradoxalmente, há uma espécie de entropia - num elemento que não se deixa apreender pela incessante captura da rede - que parece abrir uma brecha, uma linha de fuga, nessa governança global baseada no princípio de equivalência geral. Tratam-se dos fatores que, por mais que a indeterminação do real seja o propulsor do modo operacional da gestão e controle da vida no planeta, escapam, como absolutamente reais e, ao mesmo tempo, absolutamente improváveis, à apreensão por tal sistema - naquilo que Agamben chama de o ingovernável. ${ }^{31} \mathrm{Em}$ outras palavras, por trivial que pareça, face à

${ }^{30}$ É importante lembrar que o avanço desse tipo de hiperconectividade está chegando a práticas de incisão de chips em funcionários - como no caso da empresa belga Newfusion, que, segundo o seu Diretor, fez o implante a pedido dos funcionários. E, ainda segundo o empresário, há outras aplicações de tais chips, "como substituir os passaportes, os cartões de banco e cartões de transporte ou incluir informações médicas para saber o tipo sanguíneo de um ferido que ficou inconsciente e que deve ser atendido urgentemente, ou se é alérgico a algum medicamento." Cf. Instituto Humintas Unisinos. Empresa belga implanta chips em seus trabaIhadores. 21 fev. 2017.

${ }^{31}$ Cf. AGAMBEN, Giorgio. O que é o contemporâneo? e outros ensaios. Trad. Vinícius Nicastro Honesko. Chapecó: Argos, 2009. "Quanto mais os dispositivos se difundem e disseminam o seu poder em cada âmbito da vida, tanto mais o governo se encontra diante de um elemento inapreensível, que parece fugir de sua apreensão quanto mais docilmente a esta se submete. Isto não significa que ele representa em si mesmo um elemento revolucionário, nem que possa deter ou também somente ameaçar a máquina governamental. No lugar do anunciado fim da história, assiste-se, com efeito, ao incessante girar em vão da máquina, que, numa espécie de desmedida paródia da oikonomia teológica, assumiu sobre si a herança de um governo providencial do mundo que, ao invés de salvá-lo, o conduz - fiel, nisso, à originária vocação escatológica da providência - à catástrofe. O problema da profanação dos dispositivos - isto é, da restituição ao uso comum daquilo que foi capturado e separado nesses - é, por isso, tanto mais urgente. Ele não se deixará colocar corretamente se aqueles que dele se encarregam não estiverem em condições de intervir sobre os processos de subjetivação, assim como sobre os dispositivos, para levar à luz aquele Ingovernável, que é o início e, ao mesmo tempo, o ponto de fuga de toda política." 
máquina de controle das probabilidades que nos submete à lógica de um único real possível - este que se nos impõe a partir de seu local de produção e que, como lembra Certeau, nos seduz com as vozes charmosas de uma narração que impele à crença e produz seus praticantes -, o informalizável da vida ainda carrega uma potência do impossível, isto é, não tem como ser apreendido numa máquina narrativa, num sistema de informação, numa rede de rastros digitais mas pode, isso sim, ser um modo de paralisar tal sistema.

Os corpos, os corpos reais, ainda não foram transformados em dados, em narrativa, e é a partir deles, esse ponto fora de formalização, que podemos destruir essa primeira formalização que nos é imposta e aceder a um outro real, àquele impossível a que foi feito referência no início. $\mathrm{E}$, assim, talvez a máxima "sejamos realistas, exijamos o impossível!" possa ser pensada à luz da Sexta Tese sobre o Conceito de História de Walter Benjamin: "O dom de atear ao passado a centelha da esperança pertence somente àquele historiador que está perpassado pela convicção de que também os mortos não estarão seguros diante do inimigo, se ele for vitorioso. E esse inimigo não tem cessado de vencer." ${ }^{32}$ Esse inimigo não deixa de nos impor seu real - e hoje com o canto mais doce do que o de sereias -, mas cabe a nós demandar esse impossível que, na narrativa do inimigo, é obliterado por uma suposta benevolência travestida em palavras de ordem nas quais querem nos fazer crer: "Fazemos todo o possível para que as coisas melhorem." Não é desse vergonho possível que hoje é preciso se nutrir uma luta histórica. Pelo contrário, aniquilar essa suposta única realidade possível parece ser nossa tarefa.

32 BENJAMIN, Walter. Teses sobre o conceito de História. In: LOWY, Michel. Walter Benjamin: Aviso de Incêndio. Trad. Jeanne Marie Gagnegin e Marcos Lutz Müller. São Paulo: Boitempo, 2005, p. 65. 